\title{
Positive Psychology Program: Stress And CoatingPrograma De Psicología Positiva: Estrés Y Recubrimiento
}

\author{
Edmundo Cabezas - Heredia ${ }^{a}$, Gabriel Arturo Pazmiño Solys ${ }^{b}$, Mónica Salazar Tapia ${ }^{c}$, Clarita Vanessa \\ Gavilánez Cárdenas ${ }^{\mathrm{d}}$
}

\author{
${ }^{a}$ Facultad de Ingeniería, Escuela de Ingeniería Agroindustrial, Universidad Nacional de Chimborazo, Ecuador \\ ${ }^{\mathbf{b}}$ Facultad de Ciencias de la Ingeniería y Aplicadas, Carrera de Ingeniería Industrial, Universidad Técnica de Cotopaxi, Ecuador \\ ${ }^{\mathbf{c}}$ Facultad de Ciencias Administrativas, Carrera de Gestión de la Información Gerencial, Universidad Técnica de Cotopaxi, \\ Ecuador \\ ${ }^{\mathrm{d}}$ Facultad de Administración de Empresas, Gestión Empresarial e Informática, Universidad Estatal de Bolívar, Ecuador

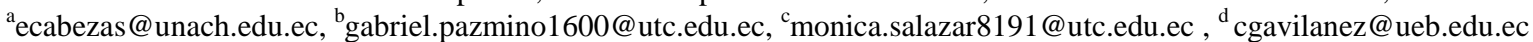

Article History: Received: 10 November 2020; Revised 12 January 2021 Accepted: 27 January 2021; Published online: 5 April 2021

\begin{abstract}
The purpose of this study was to determine the relationship between coping strategies and stress in the workers of the Food Company "ARSAICO" of the Canton Chambo - Ecuador. The study population is 20 workers that is the entire company, sociodemographic variables are considered for the study, this research is quantitative approach, descriptive type with non-experimental correlational and cross-sectional design. The tests applied were the COPE questionnaire for coping and WHO - ILO for stress. For the information processing, the statistical program SPSS version 24 and the Spearman correlation coefficient were used, finding a significant inverse relationship between stress and coping. Regarding the analysis between before and after the program, positive psychology decreases stress levels from medium to low with high coping..
\end{abstract}

Keywords: Positive Psychology Program, Stress, Coping.

\section{Introduction}

This research on stress and coping in times of the COVID-19 pandemic in workers of the food company "ARSAICO" of the canton Chambo, through the application of the work stress test designed by the International Labor Organization (ILO) and the Organization World Health Organization (WHO) and the Brief COPE coping test to determine levels of stress and coping in the presence of COVID-19.

The arrival of the COVID - 19 pandemic in Ecuador has changed the socioeconomic environment and work aspect, confinement has contributed to the development of negative emotional aspects such as the increasing rates of infections and deaths in the population causing psychological alterations. (Caballero \& Campo, 2020), mentions that stress "has sequelae with the neurobiological part since it increases the probability of worsening concomitant diseases, increasing possibilities to create a mental disorder such as: anxiety, depressive, sleep disorders and subtle stress".

When the person cannot control their environment and the challenges that are presented to them, they encounter symptoms of stress, overcoming it depends on their ability to deal with it successfully, knowing that this scenario can endanger their physical and psychological well-being. (Horna, 2016).

When the person cannot control their environment and the challenges that are presented to them, they encounter symptoms of stress, overcoming it depends on their ability to deal with it successfully, knowing that this scenario can endanger their physical and psychological well-being. (Horna, 2016).

The adult population that works in the agro-industrial sector has specific characteristics and needs; It is a dynamic human and work group that needs to reinforce its healthy lifestyle for good work performance. (Ferrando Perea, 2016).

For Caballero \& Campo Arias, (2020) psychological responses to a pandemic are usually light, but long-term emotional results are observed; that depend on the characteristics of the individual, such as intolerance to uncertainty, susceptibility to illness, anxiety or depression.

According to Horna, (2016), stress is a type of physical and emotional response that we will experience when we face a change in our life, this response can have both positive and negative effects, the body begins to act automatically and naturally in the face of threatening scenarios, challenging as the case of the pandemic. 
For Regueiro, (2016), to face stress and adapt to various situations, demands that arise, one must act as a response to solve problems despite insufficient resources.

According to the OIT, (2016) stress stimulates an imbalance between the appreciated requirement, resources and capacities of the person to face it through emotions and physical aspects.

According to Delgado, (2004), workers who go through difficulties affect their health and work performance, stress originates at work due to their permanence in it, it is related and develops an effective response to stress for successful adaptation.

For Delgado, (2004) the effects of stress cause alteration in the functioning of the nervous system, affects the brain and will produce behavioral disorders. Among the negative effects produced are: excessive restlessness, inability to make decisions, effect of confusion, lack of concentration, attention problems, feelings of lack of control, feeling of disorientation, usual forgetfulness, bad mood, and greater probability of accidents and consumption of drugs, alcohol and tobacco.

In the company, absenteeism causes a large number of planning problems, logistics and stress in people, leading to production losses and can result in a bad work environment. (Delgado, 2004).

Coping comes from the English word Coping, it is used for studies related to stress and adaptation to stressful situations (Soucase et al, 2005).

Lazarus and Folkman coping is an issue that is identified by the "efforts" made by an individual through the evaluation of his environment that feels threatening his resources, they have no other purpose than to promote adjustment (in psychological and social terms ) or the adaptation (in biological terms) of that person. (Piña, 2009.

For Proaño (2014) the way to face the situation depends on the strategies used by people, there are two types of strategies: the strategy focused on the problem in which the situation is changed by solving the problem and the strategy focused on emotions controls the negative esters or emotional differences that the situation generates. the situation depends on the strategies used by people, there are two types of strategies: focused on the problem and solving it; the strategy focused on emotions controls the negative or different esters that the situation generates.

Positive psychology studies well-being, also of character, being the set of stable traits that define the person. This approach is focused on studying good character, such as those traits with moral and axiological value found in the personality structure that make individual differences possible (Gancedo, 2007). Peterson and Seligman (2004) establish the definition of character as a set of human virtues operationalized in the concrete in the strengths, which change according to the context.

Las fortalezas del carácter son definidas como formas íntimamente valiosas de tolerar, pensar y sentir que promueven el bienestar, las relaciones positivas y el logro exitoso de metas (Peterson y Seligman ,2004). Este constructo multidimensional, contiene un conjunto de 24 rasgos valorados en diversas culturas clasificadas en 6 virtudes (Park et al., 2013). Este catálogo de virtudes y fortalezas del carácter resultado del análisis de textos ancestrales sobre el entorno de las virtudes desde la visión confuciana, taoísta, budista, hinduista, griega clásica, judeocristiana y las tradiciones musulmanas. (McGrath, 2015).

Faced with this described problem, stress in the workplace and its effects on workers affects: decreased concentration at work, lack of energy to perform activities causing a low quality of work, having less job security, anxiety, depression, etc.

From this perspective, how workers at the food company "ARSAICO" cope with work stress after the arrival of the COVID-19 pandemic, which caused such abrupt socio-productive changes in the company.

\section{Method}

\section{Design of the investigation:}

The study is of an exploratory-descriptive type characterized by a fact or phenomenon in a study group, for Meyer, (2006), which consists of getting to know the outstanding situations, customs and attitudes through the specific description of the activities, objects, processes and people, its goal is the prediction and identification of the relationships that exist between two or more variables.

It is mixed quali-quantitative, the degree of relationship between two variables was analyzed, for Creswell, (2009), it facilitates a better understanding of the research problem, the study is of a longitudinal type with a before and after to collect the data and therefore the presence of COVID-19, a questionnaire was applied in Google Forms that was disseminated through the link to the WhatsApp of the company's workers. In total, all 
workers with 20 people were surveyed. The database was programmed in SPSS V.24 and an analysis of the response items was carried out by question, dimension of the subjects.

\section{Kind of investigation:}

The research is in the field since surveys were conducted on work stress by ILO-WHO and coping with COPE in the facilities of the food products company "ARSAICO" in the canton of Chambo.

The OIT and OMS questionnaire allows to measure the level of work stress that the study subjects have to evaluate, which consists of 25 items related to work stress as well as 7 alternatives as responses that range from the score from 1 to 7 , from "never" to "always"

Table 1.Scale of dimensions of the OIT test

\begin{tabular}{|l|l|}
\hline Dimensions & Ítems \\
\hline $\begin{array}{l}\text { Organizational climate } \\
\text { Organizational structure }\end{array}$ & $\mathbf{1 , 1 0 , 1 1 , 2 0}$ \\
\hline Organizational Territory & $3,15,16,24$ \\
\hline $\begin{array}{l}\text { Technology } \\
\text { Leader influence }\end{array}$ & $4,14,25$ \\
\hline Lack of cohesion & $5,6,3,17$ \\
\hline Group support & $7,9,18,21$ \\
\hline
\end{tabular}

Source: (Irribarren, 2019)

\section{Test evaluation:}

Table 2. Assessment of the OIT-OMS stress test

Source: (Irribarren, 2019)

\begin{tabular}{|l|c|}
\hline \multicolumn{2}{|l|}{ Assessment } \\
\hline Low stress level & $<90,2$ \\
\hline Intermediate level & $90,3-117,2$ \\
\hline Stress & $117,3-153,2$ \\
\hline High stress level & $>153,3$ \\
\hline
\end{tabular}

\section{Subjects:}

The study subjects are those people or groups of people that are part of the groups whose characteristics, opinions, experiences, living conditions, among other traits and attributes are of particular interest for research with a quantitative or qualitative approach, in this research they are the 20 workers of the food company "ARSAICO" who face job stress after the arrival of the COVID-19 pandemic, which caused such abrupt socioproductive changes in the company.

Sections and Materials

The sections and Materials and methods for this investigation are described below: 


\section{Brief COPE coping test:}

The Brief COPE questionnaire is made up of 28 items which has 2 dimensions and 14 subdimensions with two items each, the scales are as follows: a) Active, b) planning, c) positive reformulation, d) acceptance, e) humor , f) emotional support, g) institutional support, i) self-distraction, j) denial, k) emotional rest, l) substance use, m) religion, n) self-blame.

This questionnaire also has dimensions which are of active coping, which are the first 7 sub-dimensions that are efforts made to face the difficulty directly and the other 7 are of passive coping, which seeks to avoid a situation that is presenting Absence of four subscales which are presented on a scale that goes from their possible answers are: (1) Almost never, (2) Sometimes, (3) Usually, (4) Very often.

Table 3. Brief COPE Test Scale

Source: (Morán, et al., 2010)

\begin{tabular}{|l|l|}
\hline Strategy & Ítem \\
\hline Active coping & 2,10 \\
\hline Planning & 6,26 \\
\hline $\begin{array}{l}\text { Emotional } \\
\text { Support }\end{array}$ & 9,17 \\
\hline Social support & 1,28 \\
\hline Religion & 16,20 \\
\hline $\begin{array}{l}\text { Positive } \\
\text { reassessment }\end{array}$ & 14,18 \\
\hline Acceptance & 3,21 \\
\hline Denial & 5,13 \\
\hline Humor & 7,19 \\
\hline Self-distraction & 4,22 \\
\hline Self-incrimination & 8,27 \\
\hline Disconnection & 11,25 \\
\hline Substance use & 15,24 \\
\hline
\end{tabular}

\section{Test evaluation:}

Table 4. Assessment of the Brief COPE Test

\begin{tabular}{|l|l|}
\hline \multicolumn{2}{|l|}{ Assessment } \\
\hline Low coping stress & 0 a 37 \\
\hline Medium Coping & 38 a 74 \\
\hline High Coping & 75 a 112 \\
\hline
\end{tabular}


In the SPSS V24, the sociodemographic data of the participants was collected, designed with closed responses, they were asked about their age, sex, among others.

\section{Procedure}

With the data obtained in both questionnaires, descriptive analyzes were carried out to study the frequencies of symptoms of depression, anxiety and stress stratified by sociodemographic variables and compared with the level of coping of the people.

\section{4. $\quad$ Results}

Twenty workers from the ARSAICO food company participated in the entire study. The samples were taken through Google Forms. Specifically, among the surveyed population, 45\% $(\mathrm{n}=9)$ were men and $55 \%(\mathrm{n}=11)$ were women. $80 \%$ single $(n=16), 20 \%$ married $(n=4)$, Regarding the level of education $50 \%(n=10)$ with primary education, $40 \%$ secondary $(n=8)$ and $10 \%$ higher $(n=2)$. The ages fluctuate from 18 to 30 years $65 \%(n$ $=13)$, from 31 to 45 years $35 \%(n=7)$. This is what refers to the sociodemographic variables.

To determine the level of stress and coping, a before and after were established in two stages, these being the following:

\section{Before:}

Table 5. Assessment of stress before the implementation of the proposal.

\begin{tabular}{|l|c|c|}
\hline \multicolumn{1}{|c|}{ Level Prequency } & e \\
\hline $\begin{array}{l}\text { Low stress } \\
\text { level }\end{array}$ & 4 & 20,0 \\
\hline $\begin{array}{l}\text { Intermediate } \\
\text { level }\end{array}$ & 13 & 65,0 \\
\hline $\begin{array}{l}\text { Presence of } \\
\text { stress }\end{array}$ & 3 & 15,0 \\
\hline \multicolumn{1}{|c|}{ Total } & 20 & 100,0 \\
\hline
\end{tabular}

There is an intermediate and high level of stress that must be dealt with through the Positive Psychology program.

Table 6.Assessment of coping before the implementation of the proposal

\begin{tabular}{|c|c|c|}
\hline \multicolumn{2}{|c|}{ LevelFrequency } & ge Percenta \\
\hline $\begin{array}{c}\mid 2 \\
\text { um }\end{array}$ & 18 & 90,0 \\
\hline High & 2 & 10,0 \\
\hline Total & 20 & 100,0 \\
\hline
\end{tabular}

There is a medium-high coping that can be provided that is by an intuitive way of defending each person before a problem. 


\section{Then:}

Table 7. Stress assessment after implementation of the proposal

\begin{tabular}{|c|c|c|}
\hline \multicolumn{2}{|c|}{ LevelFrequency } & Percentage \\
\hline Low & 17 & 85,0 \\
\hline $\begin{array}{c}\text { Medi } \\
\text { Motal }\end{array}$ & 3 & 15,0 \\
\hline To & 100,0 \\
\hline
\end{tabular}

After the implementation of the Positive Psychology Program, it is reduced by a majority\% to a medium-low level of stress.

Table 8. Assessment of coping after the implementation of the proposal

\begin{tabular}{|r|c|c|}
\hline \multicolumn{2}{|c|}{ LevelFrequency } & Percentage \\
\hline $\begin{array}{c}\text { um Medi } \\
\text { High }\end{array}$ & 4 & 20,0 \\
\hline Total & 20 & 80,0 \\
\hline
\end{tabular}

After the implementation of the proposal, the level of coping goes up to a good percentage.

When applying the Spearman correlation between the levels of coping and stress, it is obtained that:

Table 9. Spearman's correlation between coping and stress

\begin{tabular}{|l|l|}
\hline \multicolumn{1}{|c|}{ Value } & $\begin{array}{c}\text { Asymptotic standard error and } \\
\text { Significance level }\end{array}$ \\
\hline $\begin{array}{l}\text { Spearman } \\
\text { correlation }\end{array}$ &, 610 \\
\cline { 2 - 2 } &, 000 \\
\hline
\end{tabular}

The Spearman coefficient, both with a value of 0.610 , indicates that there is a direct relationship between the level of coping and stress with a significance value of 0.000 .

The comparison between the before and after the stress levels proposal is established, which is presented in the following figure: 


\section{Before and after:}

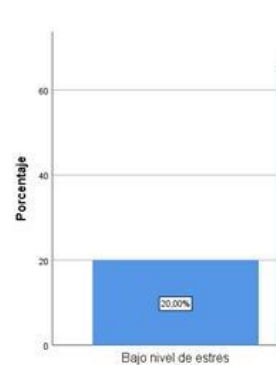

Bajo nivel de estres

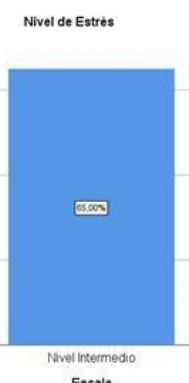

Escala

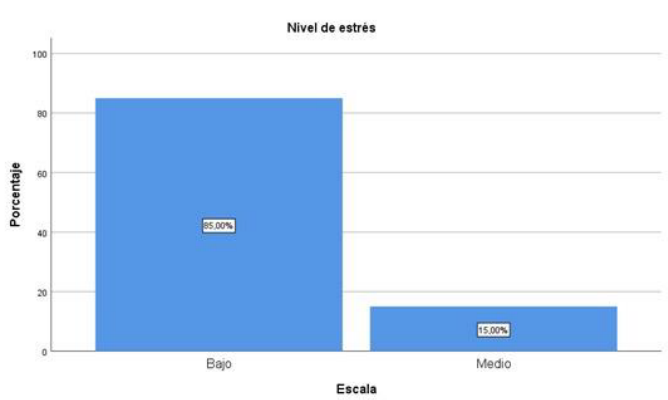

Figure 1. Spearman's correlation between coping and stress

By applying the Positive Psychology Program you can visualize the low level of stress cases.

When making a comparison between the before and after with the application of Pearson's Chi square between the observed and expected frequencies, the following result is obtained.

Table 10. Verification of the research hypothesis of stress levels and the Positive Psychology program.

\begin{tabular}{|l|l|l|l|}
\hline Value & df & $\begin{array}{l}\text { Significance } \\
\text { Asymptotic } \\
\text { (bilateral) }\end{array}$ \\
\hline Pearson's Chi-square & $8,556 \mathrm{a}$ & 1 &, 000 \\
\hline N of valid cases & 20 & \\
\hline
\end{tabular}

With a value of $\mathrm{Xc2}=0.000$ we note that these values do not exceed the significance value (0.05), so stress levels decrease with the application of the Positive Psychology program.

In the same way, a comparison is made between the observed and expected frequencies of stress and coping with the following result:

Table 11. Verification of the research hypothesis of stress levels and coping.

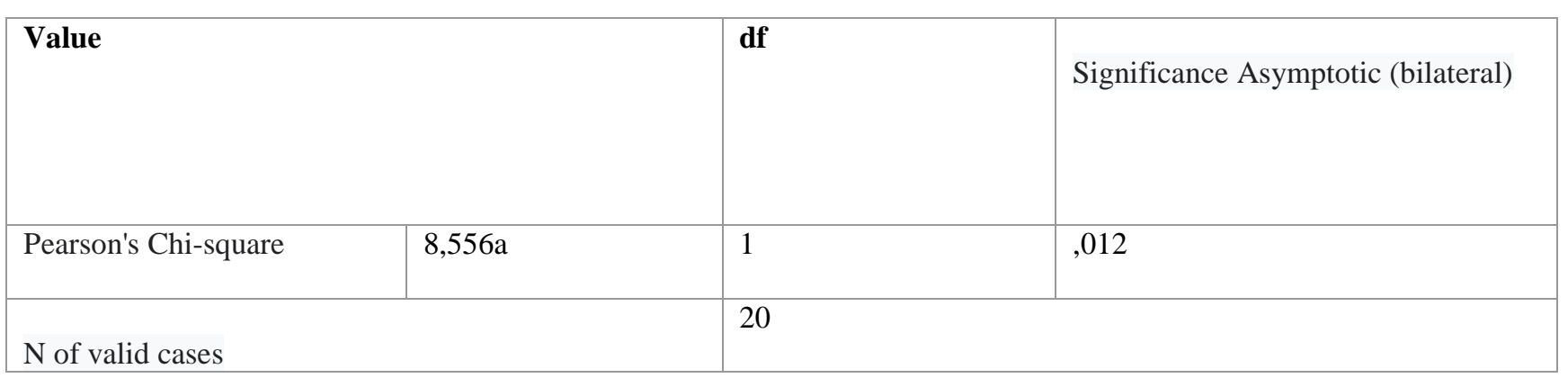

With a value of $\mathrm{Xc2}=0.012$, we note that these values do not exceed the significance value $(0.05)$, so stress levels decrease with adequate coping.

\section{Discussion}

Regarding the stress levels before the implementation of the Positive Psychology program, it was observed that these are moderate to high, which could be due to the application of the quarantine test for the presence of Covid19 and the performance of tasks for teleworking, absence of biosafety protocols. However, these levels are not encouraging. It raises concern. It is necessary to monitor the phenomenon under study.

It is worrying since when analyzing the stress component, it was observed that the emotional indicators were medium high, that is, workers would be more aware of their stress signals based on their affective responses to the presence of the virus and the new work environment. 
The stress levels after the implementation of the program is medium low, so stress management in this population places more emphasis on its affective components, so that an adequate identification is achieved and the presence of stress indicators can be prevented. more chronic, which definitely affect people's health.

Coping before implementation is medium high, which increases by a significant high\% due to the more frequent use of positive reinterpretation strategies, seeking social support for emotional reasons and planning. While the least used strategies are denial, behavioral misunderstanding and turning to religion.

By establishing the Spearman correlation, a non-parametric measure used to compare the two variables for small populations such as the case study in which values close to 1 ; indicate a strong and positive correlation. Values close to -1 indicate a strong and negative correlation; in this case it is positive and close to 1 , there is a relationship between coping and stress.

The significance level of 0.000 and 0.012 respectively for stress, coping and Positive psychology program accepts the research hypotheses in which an adequate coping based on a Resilience Psychological Well-being Intervention Program reduces stress levels as manifested (Truan et al, 2020) and through ways of overcoming the stressor can recover with adequate coping.

In the research work that carried out an analysis of work stress and coping with the health emergency requires a great capacity for decision-making of the workers, that is why it is important to take care of its aspects: mental, emotional and behavioral, knowing the level of coping through the COPE test and work stress through the OITOMS test in which two evaluations were made with the same type of surveys and when determining medium-high levels, the preventive health and safety program was applied based on the positive psychology and training, managing to reduce the level of stress at levels under the highest percentage of workers.

\section{Conclusions}

It is concluded that at present and when living with COVID-19, it is evident that in the workers of the Food Company "ARSAICO" of the Canton Chambo - Ecuador, there is a high level of stress in the labor field that affects: decreased concentration at work, lack of energy to carry out activities causing a low quality of work, having less job security, anxiety, depression, etc. Upon showing the stress, the managers proceeded to take care of the aspects: mental, emotional and behavioral, through the preventive health and safety program based on positive psychology and training, managing to reduce the level of stress at levels below the highest percentage of workers.

The level of coping by the workers of the food products company "ARSAICO" could be evidenced an intermediate level of $90 \%$ of the workers and $10 \%$ present a high level, in the presence of COVID-19 with a difficulty of adapting to the new regularity.

The correlation between the variables coping and stress at work is 0.610 , which is close to 1 , it is high as the level of coping increases, the level of stress in workers decreases with the application of the Positive Psychology Program.

The application of the OIT-OMS|| work stress test assesses the existing work stress levels with an intermediate stress level - high mostly due to the presence of COVID-19, being able to show that workers have not learned to cope with the new reality, their style and quality of life being affected, which decreases to a low with the application of the Positive Psychology Proposal.

The proposal to reduce the levels of work stress through the application of the preventive program based on positive psychology that is structured in 4 phases that contains aspects such as: active breaks, talks, recreational aspects with biosafety protocols, etc

\section{References}

Caballero, C., \& Campo, A. (2020). Mental health problems in society: An approach from the impact of COVID 19 and quarantine. Duazary, 17 (3), pp 1-3

Creswell, J. W. (2009). Mapping the Field of Mixed Methods Research. SAGE JOURNALS, 95-108.

Delgado, M. A. (2004). Work stress. Madrid: National Institute of Safety and Hygiene at Work.

Ferrando Perea, A. (2016). Impact of the organizational climate on work stress in agroindustrial companies. Dialnet, 62.

Gancedo, M. (2007). Virtues and strengths: The reverse of the plot. Psychodebate, 7, 67-80. Doi: 10.18682 / pd.v7i0.428

Horna, F. H. (October 26, 2016). Job satisfaction and job stress in workers. Obtained from Thesis:http://200.62.226.186/bitstream/upaorep/2458/1/Re_psico_fiorella.horna_satisfaccion.laboral.y.estres.1 aboral.En.trabajadores.de.una.institucion_datoss.conducta_datos.PDF 
Irribarren, M. (2019). ILO Work Stress Scale WHO. Retrieved June 06, 2020, from https://www.academia.edu/27633486/ESCALA_DE_ESTRES_LABORAL_DE_LA_OIT_OMS.

McGrath, R. E. (2015). Character strengths in 75 nations: An update. The Journal of Positive Psychology, 10 (1), 41-52. Doi: 10.1080 / 17439760.2014.888580

Meyer, D. B. (September 12, 2006). Descriptive research. Obtained from https://noemagico.blogia.com/2006/091301-la-investigaci-n-descriptiva.php

Morán, C., Landero, R., \& Gonzáles, M. T. (2010). COPE-28: a psychometric analysis of the Spanish version of the Brief COPE. Universitas Psychologica, 543-552.

ILO. (April 28, 2016). Stress at work. Retrieved from https://www.ilo.org/public/libdoc/ilo/2016/490658.pdf.

Park, N., Peterson, C. and Sun, J. K. (2013). Positive Psychology: Research and Applications. Psychological Therapy, 31 (1), 11-19. Doi: 10.4067 / S0718-48082013000100002.

Peterson, C. and Seligman, M. E. P. (2004). Character strengths and virtues: A handbook and classification. New York: Oxford University Press.

Pineapple. (2009). The original sins in Lazarus and Folkman's transactional proposal on stress and coping. Redalyc, 193-209.

Proaño Acosta, M. P. (2014). Perceptions, attributions and coping strategies of university students in the face of relationship conflicts associated with the use of the social network Facebook (Bachelor's thesis, Quito: Universidad de las Américas, 2014).

Regueiro, A. M. (April 28, 2016). What is stress and how does it affect us? Obtained from https://www.uma.es/media/files/tallerestr\%C3\%A9s.pdf.

Soucase Lozano, B., Soriano Pastor, J. F., \& Monsalve Dolz, V. (2005). Influence of mediating processes in adaptation to chronic pain. International Journal of Clinical and Health Psychology, 227-241.

Truan, J. C. F., Castellano, D. C., Ucha, F. E. G., \& Hoyos, Y. M. (2020). Psychological resilience and coping with stress in Cuban youth baseball athletes. Liminales Magazine. Writings on Psychology and Society, 9 (17), 25-37. 